\title{
Family Across Prison Walls: a Different Perspective on Incarceration
}

\author{
Anna Napadło-Kuczera*
}

Secretary of the Board, Patronat’ Penitentiary Association, Zielona Góra Branch, Poland

\begin{abstract}
Over the past 15 years, people in the the Association of Penitentiary "Patronat" have helped families of persons detained (most often the wives and children). This article describes what is done and what should be done in the area to help people in this situation, as well as the most common problems families who are trying to maintain the bonds of closeness "in spite of walls and barriers".
\end{abstract}

Keywords: Adaptation, family, inmates, rehabilitation programme.

\section{INTRODUCTION}

When you are feeling lonely and helpless, you are not able to properly counteract pressures from the environment. Then an individual finds it really hard to say 'no' to a pressure-exerting group. This is particularly the case with young people, whose personality structure is still in development. They are in fact steered by the society. The question is whether this influence is beneficial or destructive. The same pressures are exerted on adults, people whose personality and character have already been formed.

An incarcerated person is already somewhat a product of the aforementioned pressures. As a matter of fact, such persons may be merely an outcome of socialisation in the broad sense of the term. The world around should raise public awareness and understanding of the needs and problems of convicts. After all, not all of them are totally unscrupulous and ruthless. Everyone needs support and the sense of being accepted. Everyone has the right to human dignity and love.

We know that the goal behind incarceration is to "encourage the convict to participate in developing socially desirable attitudes in them, in particular the sense of responsibility and the need to obey the law, thus not repeating their crimes" (Penal Executive Code, 1978, art. 67). To achieve the aforementioned goal, the Prison Officers has two basic tasks:

1. Correctional and rehabilitative efforts oriented towards convicts, mainly through organising work to enhance their professional skills, teaching, cultural and educational activities, as well as dedicated therapeutic interventions; and

2. Protecting the society from convicts confined in correctional institutions and those in custody (Journal of Law, 2014).

*Address correspondence to this author at the Secretary of the Board, Patronat' Penitentiary Association, Zielona Góra Branch, Poland;

E-mail: aneczka.n@poczta.fm
When addressing these two tasks, it appears difficult to make clear-cut choices. We are facing the eternal dilemma: rehabilitation or isolation? These are the functions of incarceration after all. It is hard to find a straightforward answer. Who should decide about this? How to find the right balance between these two approaches, seemingly so contradictory? Is it for us to decide the right way to go? Psychologists and policy makers, as well as practitioners directly involved in making these choices, are at crossroads and keep asking themselves the same question: what is better? Yet, no one can give a forthright answer.

Maybe it would be a good idea to look for a different solution? Is there any? There is the recognition that maintaining contacts with the outside world is crucial for convicts, both for their psychological well-being and the entire rehabilitation process with the resulting re-adaptation. The Executive Penal Code lays down pedagogical goals behind imprisonment, and introduces a normative definition of rehabilitation. Measures and methods are provided, along with their expected results (Penal Executive Code, 1978, art. 44).

It should be remembered that the natural family brings together biological, social and cultural factors. Its role in supporting a child's development at different life stages constitutes either diminishing or enhancing environmental pressures. Different factors impact an individual through specific pressures from the environment. Impacts can be divided into direct and indirect. For example, all impacts within the family and at school are direct in nature, while those related to culture have an indirect influence on the child (Kawula, 1999). Thus, it may be concluded that if an individual fails to gain relevant experiences in childhood, or gains defective ones, they will later face problems adjusting to a life under socially accepted conditions. Human development also depends on the sequence of these impacts. Therefore, what is important in creating development paths is the family and how an individual functions in a given cultural setting (Turner, 2012). In 1957, analyses were made in the Szczypiorno prison facility on family's impact on the rehabilitation of convicts, in particular juveniles 
(Machel, 1989). Rehabilitation pedagogy suggests that maintaining ties between prisoners and their families is indispensable. If such ties are successfully maintained, inmates' psychological hygiene is greatly improved and their motivation to behave well in prison may grow stronger. Undoubtedly, it also gives the sense of being needed and loved, something that is indispensable for everyone. An imprisoned convict has been artificially separated from his or her family and the direct family influence is discontinued. We are well aware that this influence could have been negative at times, but still nearly in all cases the family is the source of emotional and formal support. Under Article 105 of the Penal Executive Code, "the convict should be allowed to maintain ties, mainly with the family and other loved ones, by way of visits, letters, telephone calls, packages and money transfers, (...)" (Penal Executive Code, 1978). The family can be supported in the rehabilitation process. For this purpose, the prison tutor should influence to a certain degree a convict's contacts with his or her family by regulating the frequency, form and duration of such contacts. This effort strengthens family bonds and positive motivation and, as a result, is conducive to social adaptation that follows later.

\section{EXPERIENCES}

Since it is crucial for the convict to maintain ties with the family and the "outside world", the convicted parent's contact with their child emerges as one of utmost importance. This special contact is meaningful in two ways. On one hand, it is important for the imprisoned parent, as it promotes his or her rehabilitation and later re-adaptation, and on the other hand, it is equally important for the child who is being raised without his or her mother or father.

In our daily practice, we tend to focus solely on the rehabilitation of convicts within the correctional institution. We forget about their next of kin, who are out there in the free world and face all kinds of problems and concerns resulting from the fact that their loved ones are imprisoned. It would be worthwhile to take their experiences and feelings connected with such separation into consideration as well. Are there any innovative solutions in place to bring incarcerated parents closer to their children staying outside the prison walls?

In order to address these concerns, the Zielona Gora Branch of the 'Patronage' Penitentiary Association organised and carried out a pilot project back in 2004. Under that project, a group of four convicted women from the Correctional Institution in Krzywaniec went on a 7-day holiday at the lake in Sława together with their children. Project participants had been selected by the prison staff. Unfortunately, their number could not have been higher due to scarce funds of the Association at the time. During their stay in the boarding house, they were accompanied by an Association member (a volunteer and a social pedagogue by profession), whose task was to support the group in their daily activities. As organisers, we did not assume any supervision or control. The Executive Penal Code and bylaws of correctional institutions provide for a one-off 7-day pass from prison, and that was the formal arrangement chosen here (1978). The convicts were taken to the destination, whereas children were brought there by their family members. A volunteer who accompanied them recalls:

"I was apprehensive at the prospect of my weekly stay in Radzyń. I did not know what women I was going to be with for the coming week, whether they were outgoing and open, or just the opposite: reserved and with a negative attitude. It turned out that my fears had been unfounded. I met four warm and open women who had not lost their eagerness to have fun and to engage in 'normal' social life despite their difficult situation" (see Napadło- Kuczera, 2013).

The convicts spent their time in the boarding house chiefly with their children, and the children could not have been happier to have their moms only for themselves. Children found it incredibly meaningful that their moms were there to dress them up, comb their hair, tell a story and tuck them into bed. They craved all forms of physical contact: hugging, holding hands, etc. It was important for them that their moms saw them drawing pictures or bathing in the lake. It should also be mentioned that there was a holiday camp at this boarding house at the time, and children could join activities organised there (such as discos, all kinds of competitions or a campfire). Other highlights included bathing in the lake, going on pedalos, canoeing, angling and feeding ducks and swans. Project participants were clearly trying to make up for lost time and for their absence at home; they also strived to enhance their parental authority. It was not easy, as it is hard to be a mom just for seven days, and long-distance parenting proves impossible. It was plain to see that this situation was a source of great distress for children. Some of them were not aware of the fact that their mom was in prison. They found it hard to accept that their mom keeps 'going away for work' and cannot get back home with them.

During their stay, convicts acted naturally and were very self-reliant. They got on very well both with children from the holiday camp and holidaymakers staying in nearby summer cottages (they would play volleyball together). They were relaxed, and viewed their stay in Radzyń as a chance to get some rest from their daily hardships. Yet, they kept coming back to their imprisonment in conversations. Every woman has shared her 'prison story' and told how difficult it was for her to live away from her family. They said many times that this holiday was a really good thing for them. Not only could they spend some time with their children, but also feel like free people for a moment, just like ordinary moms spending holidays with their kids. The time they had together helped them get to know each other better, as they had not have such an opportunity so far. From early on, they decided to 'stick together' and so they did till the very end. This unique 'solidarity' manifested itself in sharing childcare, leisure activities (swimming in the lake, playing volleyball and cards and organising a barbeque) or disbursing and preparing meals. They would return to their cottages only for the night, actually. They stayed outdoors all day along.

Given the fact that the pilot project had been successful and had achieved its initial goals, in 2006 and 2007 we organised 'holiday with mom' again. Yet, this time children met their moms in the boarding house at the Correctional Institution in Krzywaniec. 
An ordinary person living outside prison walls believes that money should not be spent on convicts, on their counselling and support. Unfortunately, there is a lingering stereotype that if someone is 'behind bars' then this must be a bad person who probably got their just deserts. One could not be more wrong... Being away from the family every single day and away from beloved children is devastating for the heart, and later for the mind, particularly in the case of women. Parents who cannot be there for their kids on a daily basis do not ask for much. Moms simply wanted to be with their children... to go for a walk together, talk, laugh, prepare milk for breakfast, just be there... It is not much in fact, yet the society is strongly against it. Fortunately, the correctional institution managers share our views; therefore, we may employ practical means to prevent the convicts from relapsing into crime, and thus rehabilitate them effectively. In fig. (1) you can see mothers and fathers spend time with theirs kids during the aforementioned holidays.

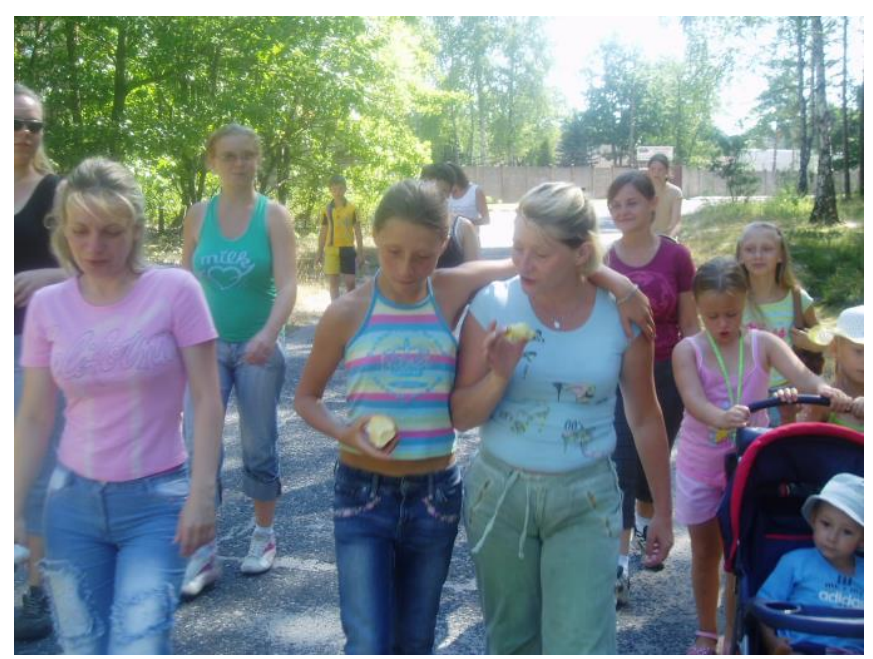

(a)

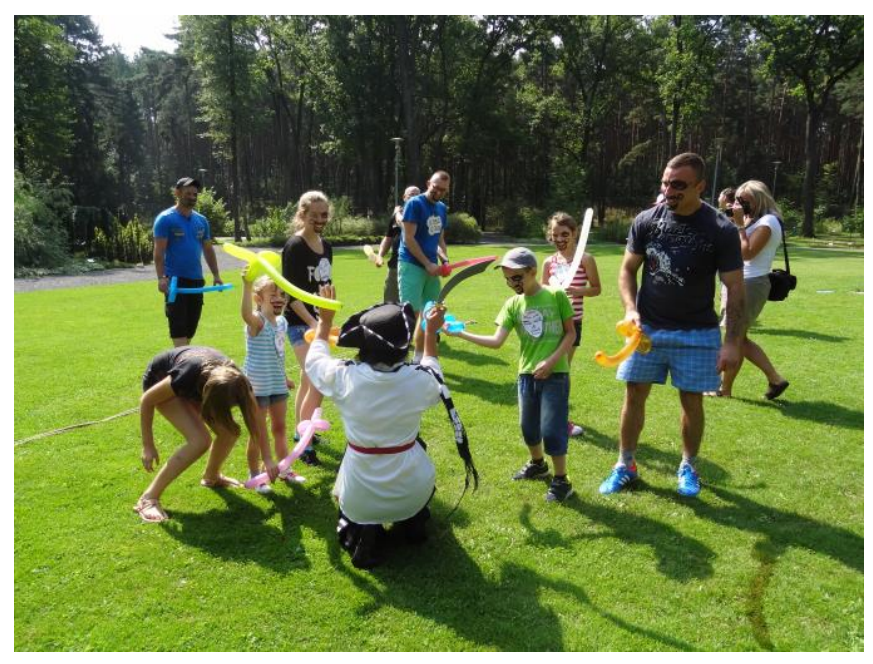

(b)

Fig. (1), (a,b). Mothers and fathers spend time with kids.

In the summer of 2014, similar holiday for fathers and their children was organised for the first time. Stereotypes and misassumptions might have won again, if we were to think that fathers' bonds with their children are not as strong as those of mothers, and that they would not handle daily routines and taking care of their children for nearly a week. Fortunately, it proved otherwise. Frolicking, joy and, most of all, love, went on and on.

There were three siblings that caught everyone's attention. Before their father was incarcerated, all children had been staying with him and received great support and love from him. Now they were living apart, and each had a personal drama of their own. It is difficult for them to stay in touch, and they are all actually waiting for the moment when their dad takes them back home. Here is what the youngest sister said about those six days they had spent together:

"My memories from holiday spent together with my dad and siblings. On the first day, we met with dad and others, but the most important thing was that I could meet my brother and sister, whom I had not seen for a long time. (...) When we leave tomorrow, I will miss my dad, and if there is an opportunity we will finally live together. I would really want it to be like in the old days. I would be with my siblings".

The 15-year-old girl put it like this:

"I had a great time with my dad, I met interesting people, and most of all, I could finally spend some time with my siblings. Time flew too fast (...) I am really happy to be here because it has been a while since I had such a good time. (...) I cannot find words to describe how I feel. It has been wonderful and it makes me sad to think I must go back 'home'. I would truly like to spend some more time with my family, with my dad and siblings".

Their 17-year-old brother put emphasis on the following aspects:

"My memories are mainly about finally meeting my dad, whom I had not seen for a long time, and about doing things together with him like we used to a couple of years ago. During this holiday we have finally found common ground we both had missed. I guess just like everyone who sees their father after a long time, I had this feeling inside at first and I felt a relief that I will now talk to him, even if only for a couple of days, and also learn many things from him, like jumping into water with head down I have just learned recently. My second memory will be about finally meeting my sisters, whom I had not seen for a while, as well, and now we are sitting together at one table, talking and laughing. All this will stay in my memory, and when I recall this holiday, I will smile and carry on, despite all my sorrows (...)".

After the holiday for fathers, holiday for mothers was organised. With the support of the Polish Ministry of Labour and Social Policy, under the Civic Initiatives Fund, a total of 10 convicts from the Correctional Institution in Krzywaniec joined the project this summer. The words of these three children quoted above speak for themselves, and these are just three out of 18 family members. In our daily work we focus on convicts, who in fact have roof over their heads, board and lodging along with the support from the correctional department. Unfortunately, we tend to forget about those who stayed home or entered into other temporary artificial arrangements. From among 18 family members who participated in holiday meetings this year, none has 
received any psychological or pedagogical counselling in their local community. Under the described project, we tried to offer them at least a minimum of psychological and pedagogical support throughout their entire holiday stay. It is just a drop in the ocean though.

\section{SUMMARY}

Holidays presented above can be some sort of a 'golden means' for the question that has been posed in the introduction, i.e. rehabilitation or isolation. A pass from prison lasting a couple of days has become a kind of an award here for women selected by prison tutors (this year, also for men). What a paradox: meeting the family is an award ... However, under these circumstances, such statement seems justified. Being a pedagogue, I know that humans cannot live outside the society, and that they are being shaped and formed by it. The contact with their primary group, i.e. family, is of utmost importance. As a member of the board of Zielona Gora Branch of our Association, I hope that these projects and undertakings will become regular events all over Poland, and not just in the Correctional Institution in Krzywaniec. Let us not be afraid of going against the flow and taking up innovative solutions, because family is a top priority.

\section{CONFLICT OF INTEREST}

The author confirms that this article content has no conflict of interest.

\section{ACKNOWLEDGEMENTS}

Declared none.

\section{REFERENCES}

Journal of Law. (2014). Act of 9 April 2010 on Prison Officers, Item173, Article 2, Section 2, Warszawa: Polish Ministry of Justice.

Kawula S. (1999). The Impact of Various Relationships on Human Development. Toruń, Poland: Akapit Press .

Machel, H. (1989). Increased contact with the family as a factor that contributes to the social rehabilitation of convicts. Penitentiary and Criminological Overview, 16, 61-65.

Napadło-Kuczera, A. (2013). Ten years of the Penitentiary Association "Patronat" Branch in Zielona Gora. In: Lipińska-Lokś, J., Miłkowska, G., and Napadło-Kuczera, A., Eds., The outer and inner aspects of individual and collective security (pp. 107-120). Zielona Góra, Poland: Zielona Gora University Press.

Penal Executive Code. (1978). Polish prison system. Warszawa: Polish Ministry of Justice.

Turner, J.H. (2012). The Structure of Sociological Theory. Warszawa, Poland: PWN.

Received: November 28, 2014
(C) Anna Napadło-Kuczera; Licensee Bentham Open.

This is an open access article licensed under the terms of the Creative Commons Attribution Non-Commercial License (http://creativecommons.org/licenses/ by-nc/3.0/) which permits unrestricted, non-commercial use, distribution and reproduction in any medium, provided the work is properly cited. 